\title{
Effect of ramosetron on QTc interval: a randomised controlled trial in patients undergoing off-pump coronary artery bypass surgery
}

Tae Kyong Kim', Youn Joung Cho', Chae-won Lim², Jeong Jin Min³ ${ }^{3}$ Eue-Keun Choi ${ }^{4}$, Deok Man Hong ${ }^{1}$ and Yunseok Jeon ${ }^{*}$

\begin{abstract}
Background: Ramosetron is a relatively new 5-hydroxytryptamine three receptor antagonist with higher binding affinity and more prolonged duration of action compared to ondansetron. The present study was performed to evaluate the effects of ramosetron on QTc interval and possible cardiovascular adverse effects in patients undergoing cardiac surgery.

Method: A total of 114 patients who underwent off-pump coronary artery bypass surgery were enrolled in this randomised placebo-controlled trial. Patients were allocated into two groups that received intravenous injection of $0.3 \mathrm{mg}$ ramosetron or normal saline during induction of anaesthesia. QTc intervals were measured before the operation, intraoperatively $(0,1,2,3,5,10,15,30,45,60,90,120$, and 240 min after injection of ramosetron or normal saline), at the end of the operation, and on postoperative day 1.

Results: There were no differences in mean QTc interval between groups at every time point. However, maximal change in QTc interval during surgery was higher in the ramosetron group than the placebo group (25.1 \pm 22.0 vs. $17.5 \pm 14.5 \mathrm{~ms}$, $95 \% \mathrm{Cl} 0.34-14.78, P=0.040$ ). Also, there were more patients with a QTc interval increase of $>60 \mathrm{~ms}$ in the ramosetron group (5 vs. 0, $95 \% \mathrm{Cl}$ 1.6-18.0, $P=0.021$ ). There were no significant differences in cardiovascular complications.

Conclusions: Ramosetron administered during induction of anaesthesia may affect maximal change in QTc interval during off-pump coronary artery bypass surgery. Ramosetron should be used with caution in high risk patients for developing Torsades de Pointes.

Trial registration: ClinicalTrials.gov NCT02139241. Registered November 12, 2013

Keywords: Cardiac surgery, Corrected QT interval, Ramosetron, Torsadogenic action, Serotonin 5-HT3 receptor antagonists
\end{abstract}

\section{Backgroud}

5-Hydroxytryptamine $3\left(5-\mathrm{HT}_{3}\right)$ receptor antagonists are widely used antiemetics for postoperative nausea and vomiting (PONV). However, QTc interval prolongation has been observed in a number of patients after administration of $5-\mathrm{HT}_{3}$ receptor antagonists, such as ondansetron $[1,2]$. QTc interval prolongation increases the likelihood of polymorphous ventricular arrhythmia or Torsades de Pointes

\footnotetext{
*Correspondence: jeonyunseok@gmail.com

${ }^{1}$ Department of Anaesthesiology and Pain medicine, Seoul National University Hospital, Daehakro 101, Jongno-gu, Seoul 110-744, Korea

Full list of author information is available at the end of the article
}

(TdP), which may progress to fatal ventricular fibrillation and sudden death [3]. Previous studies showed that QTc interval prolongation is associated with increased risk of cardiovascular mortality and sudden cardiac death [4-6].

PONV is not a rare occurrence in cardiac surgery patients, with incidence rates of 35 to $71 \%$ [7]. Long duration of anaesthesia, postoperative pain, and high levels of opioid use may contribute to PONV in cardiac surgery [8]. $5-\mathrm{HT}_{3}$ receptor antagonists have been used in various clinical settings, including cardiac surgery. However, patients with organic heart disease are likely to have QTc interval prolongation [9], thus $5-\mathrm{HT}_{3}$ receptor 
antagonist-associated prolongation of QTc interval in high-risk cardiac surgical patients may further increase QTc interval and may result in severe cardiac complications.

Ramosetron is relatively new $5-\mathrm{HT}_{3}$ receptor antagonist, which has higher binding affinity and prolonged duration of action compared with ondansetron [10]. A recent meta-analysis showed that ramosetron is effective for preventing PONV and reduces the incidence of PONV compared with ondansetron [11]. However, limited data are available regarding whether ramosetron increases QTc interval. As 5- $\mathrm{HT}_{3}$ receptor antagonists share a mechanism of action, we hypothesised that ramosetron would be associated with QTc interval prolongation in patients undergoing cardiac surgery. To evaluate our hypothesis, we conducted a prospective, randomised, double-blind, placebo-controlled study with evaluation of QTc interval and cardiovascular adverse outcomes by ramosetron in patients undergoing offpump coronary artery bypass graft (OPCAB).

\section{Methods \\ Patients}

This trial was registered at clinicalTrials.gov (NCT02139241) and adhered to CONSORT guidelines. The study complied with the Declaration of Helsinki and each patient gave his or her written consent to participate. There were no important changes to methods or outcomes after trial commencement and no interim analyses were performed. Adult patients scheduled for elective OPCAB were eligible for inclusion. Patients were excluded if they had preoperative treatment with inotropic agents or mechanical assist devices, heart failure with left ventricular ejection fraction less than $30 \%$, QTc interval prolongation of more than $500 \mathrm{~ms}$ on preoperative ECG, significant arrhythmia including atrial fibrillation or atrioventricular block, age more than 80 years, a history of hepatic failure (Child Class $\mathrm{B}$ or $\mathrm{C}$ ), emergency operation, renal impairment requiring renal replacement therapy, history of allergy to $5-\mathrm{HT}_{3}$ antagonists, recent exposure to medications known to cause QTc prolongation, or undergone concomitant major surgeries including general surgery, neurosurgery and orthopaedic surgery.

\section{Study design and treatments}

The study was double-blind, placebo-controlled, parallelgroup study conducted in Seoul National University Hospital, a tertiary hospital in Seoul, Korea. Patients were randomly allocated to either ramosetron group or placebo group, using a computer-generated random number table. A randomisation sequence was created with a 1:1 allocation using random block sise of 4 . An independent nurse who was not involved in the collection of data and patient care handled the random list. All patients, medical personnel, and investigators were blinded to the allocation. One researcher (D.M.H.) generated the random allocation sequence, enrolled participants and assigned participants to interventions. The independent nurse prepared $0.3 \mathrm{mg}$ of ramosetron (Nasea'; Astellas, Tokyo, Japan), the manufacturer's recommended dose or, for the control group, the same volume of normal saline.

These two medications of the same color and volume were indistinguishable to the anaesthesiologists in charge of anaesthesia. The ramosetron group received intravenous ramosetron immediately before induction of general anaesthesia, while the placebo group received intravenous normal saline according to the same schedule.

\section{Anaesthesia}

All patients received standard perioperative care. Routine monitoring included 5-lead ECG, pulse oximetry, non-invasive blood pressure, bispectral index, cerebral oximetry, continuous arterial blood pressure, pulmonary artery catheter, and transoesophageal echocardiography. A radial arterial catheter was put in place under local anaesthesia with lidocaine. Anaesthesia was induced with intravenous midazolam $0.15 \mathrm{mg} / \mathrm{kg}$, sufentanil $1 \mu \mathrm{g} / \mathrm{kg}$, and vecuronium $0.15 \mathrm{mg} / \mathrm{kg}$, and maintained with continuous infusions of remifentanil $0.5-1.0 \mu \mathrm{g} / \mathrm{kg} / \mathrm{min}$ and propofol $0.04-0.07 \mathrm{mg} / \mathrm{kg} / \mathrm{min}$, with targeting bispectral index values between 40 and 60 . We did not use volatile anaesthetics to avoid their effects on QTc interval [1214]. Arterial systolic, diastolic, and mean blood pressure, heart rate, and doses of inotropic or anticholinergic drugs were recorded at the time of induction and during the surgery. Anaesthesia-related hypotension (mean blood pressure $<60 \mathrm{mmHg}$ ) was treated with either ephedrine $0.1 \mathrm{mg} / \mathrm{kg}$ IBW (ideal body weight) (heart rate $<70$ beats $/ \mathrm{min}$ ) or phenylephrine $0.5 \mu \mathrm{g} / \mathrm{kg}$ IBW (heart rate $\geq 70$ beats $/ \mathrm{min}$ ). If blood pressure was not restored within $30 \mathrm{~s}$, the regimen was repeated until the maximum dose of ephedrine $0.5 \mathrm{mg} / \mathrm{kg}$ IBW or phenylephrine $4 \mu \mathrm{g} / \mathrm{kg}$ IBW was reached. If the blood pressure was not restored by the maximum dose, vasopressin or epinephrine was administered at the anaesthesiologist's discretion. Normothermia was maintained during the surgery with a heating mattress, warmed intravenous fluids, and a warm operating room temperature.

\section{QTc interval measurement and analysis}

Digital ECGs were recorded using a continuous monitoring ECG system (Solar 8000 M, GE Medical Systems, Milwaukee, WI, USA) at the beginning of drug administration, after $1,2,3,5,10,15,30,45,60,90,120$, and $240 \mathrm{~min}$, and at the end of the operation. ECG data in lead II were extracted with an analogue-to-digital converter (DI-149; DATAQ Instruments Inc., Akron, OH, 
USA), which was connected to the analogue output of the patient monitor, and stored on a personal computer [15]. Lead placement was consistent in the tracing of ECG. Temporally aligned superimposed ECG leads were available as an optional display. The sampling rate was $1000 \mathrm{~Hz}$. At first, the QT interval was measured using a computer-based data analysis system (LabChart7; ADI Instruments, Colorado Springs, CO, USA). ECG waves of the four consecutive cycles were averaged to acquire a more accurate representation of the ECG waveform. The QT interval was corrected according to Bazett's formula to preclude interference from heart rate $\left(\mathrm{QTc}=\mathrm{QT} / \mathrm{RR}^{1 /}\right.$ ${ }^{2}$ ). Additionally, QT interval was corrected using Fridericia's formula $\left(\mathrm{QTC}=\mathrm{QT} / \mathrm{RR}^{1 / 3}\right)$ and Hodges formula $(\mathrm{QTc}=\mathrm{QT}+1.75$ (heart rate -60$)$ ). An investigator (T.K.K.) blinded to the group allocations reviewed the ECG data and checked for possible artifacts. Noise or abnormal ECG rhythms were excluded from the QTc interval measurement. After the operation, patients were checked for arrhythmias, including atrial fibrillation, atrial flutter, ventricular tachycardia, ventricular fibrillation, bradycardia (heart rate $<50$ beats $/ \mathrm{min}$ ), and tachycardia (heart rate $>100$ beats/min). A postoperative ECG was performed to evaluate QTc interval on the morning of postoperative day 1 .

\section{Definition of postoperative complications}

The lengths of stay in the ICU and hospital were defined as the difference in days between the date of discharge and the date of surgery. Postoperative in-hospital major adverse cardiovascular and cerebral events (MACCE) were defined as a composite of death from cardiac causes, myocardial infarction, unplanned coronary revascularisation, and stroke. Myocardial infarction was defined as elevation of troponin values $(>10 \times 99$ th percentile upper reference limit) in patients with normal baseline troponin values (<99th percentile upper reference limit). In addition, new pathological $Q$ waves, new left bundle branch block, angiographically documented new graft or new native coronary artery occlusion, or imaging evidence of new loss of viable myocardium or new regional wall motion abnormality were required. Unplanned coronary revascularisation was defined as unplanned repeat percutaneous coronary intervention or CABG. Stroke was defined as a new ischaemic or haemorrhagic cerebrovascular accident with a neurological deficit lasting $>24 \mathrm{~h}$.

\section{Statistical analysis}

The primary endpoint was maximal intraoperative change in QTc interval after administration of ramosetron or placebo. The secondary endpoints were number of patients with QTc interval $>500 \mathrm{~ms}$, which is considered to increase the risk of TdP [16]; number of patients with QTc interval increase $>60 \mathrm{~ms}$, which is also considered to increase the risk of TdP [17]; presence of hypotension and bradycardia during anaesthesia induction; use of vasopressors or inotropes; presence of postoperative in-hospital arrhythmia and MACCE. Our pilot study showed that maximal change in QTc interval was $15 \pm 15 \mathrm{~ms}$ during OPCAB. Presuming that the difference of $10 \mathrm{~ms}$ in the QTc intervals was clinically significant, power analysis suggested that a minimum of 49 patients would be required for each group with a type 1 error of 0.05 and a power of 0.9. Considering a $15 \%$ dropout rate, 114 patients were recruited. Comparisons of age, weight, height, body mass index, anaesthesia time, serum electrolytes, blood pressure, heart rate, preoperative and maximal change in QTc interval, and lengths of stay in the ICU and hospital were tested with Student's t-test or Mann-Whitney U-test after testing for normality. Sex, previous medical history, use of vasopressors or inotropes, presence of prolonged QTc inter$\mathrm{val}$, and presence of postoperative complications were compared by the Chi-square test or Fisher's exact test where appropriate. QTc intervals taken serially after induction, heart rate, and blood pressure were analysed using repeated measures analysis of variance for interand intra-group comparisons. Statistical analyses were performed using the SPSS software (ver. 21.0; SPSS Inc., Chicago, IL, USA). In all analyses, $P<0.05$ was taken to indicate statistical significance.

\section{Results}

\section{Patients' characteristics}

A total of 140 consecutive patients treated from June 2013 to October 2014 were enrolled in this study. Of the 140 patients, 26 were excluded; 10 for left ventricular ejection fraction $<30 \%, 10$ for atrial fibrillation or atrioventricular block, and six for renal impairment requiring renal replacement therapy (Fig. 1). Of the 114 randomised patients, data from 11 patients could not be analysed because of poor ECG data quality or data loss. There were no cases of conversion to on-pump from OPCAB. Most surgeries began at around the same time in the morning $(87.5 \%)$; the case start time was not different between the groups. The nadir body temperature was not different between the groups $(P=0.106)$. Table 1 summarises the patients' baseline characteristics. Preoperative bradycardia, QTc interval on ECG, and serum electrolyte levels of calcium and potassium were not significantly different between the groups.

\section{Perioperative haemodynamic parameters}

The changes in heart rate and mean arterial pressure over time were significant in both ramosetron and placebo groups $(P<0.001$ and $P<0.001$, respectively $)$ 


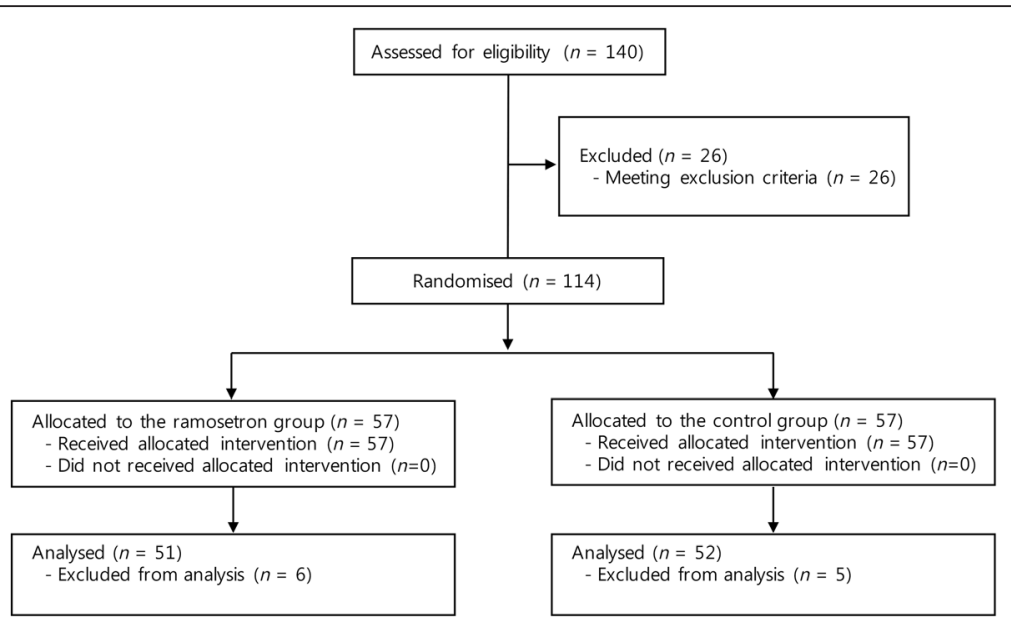

Fig. 1 Consort diagram of study participants

Table 1 Characteristics of patients receiving ramosetron or placebo

\begin{tabular}{|c|c|c|}
\hline & Ramosetron $(n=51)$ & Placebo $(n=52)$ \\
\hline Male sex & $42(82.4 \%)$ & $40(76.9 \%)$ \\
\hline Age (years) & $66.8 \pm 9.4$ & $66.0 \pm 9.9$ \\
\hline Weight (kg) & $66.0 \pm 11.1$ & $63.5 \pm 10.3$ \\
\hline Height (cm) & $164.5 \pm 9.3$ & $162.0 \pm 8.2$ \\
\hline Body mass index $\left(\mathrm{kg} / \mathrm{m}^{2}\right)$ & $24.4 \pm 3.0$ & $24.1 \pm 3.0$ \\
\hline Hypertension & $37(72.5 \%)$ & $33(63.5 \%)$ \\
\hline Diabetes mellitus & $22(43.1 \%)$ & $17(32.7 \%)$ \\
\hline 1-Vessel disease & $0(0.0 \%)$ & $4(7.7 \%)$ \\
\hline 2-Vessel disease & $6(11.8 \%)$ & $8(15.4 \%)$ \\
\hline 3-Vessel disease & $45(88.2 \%)$ & $40(76.9 \%)$ \\
\hline Previous myocardial infarction & $3(5.9 \%)$ & $4(7.7 \%)$ \\
\hline Previous stroke & $3(5.9 \%)$ & $4(7.7 \%)$ \\
\hline Current smoker & $11(21.6 \%)$ & $9(17.3 \%)$ \\
\hline Sodium (mEq/l) & $138.6 \pm 3.7$ & $139.1 \pm 2.9$ \\
\hline Potassium (mEq/l) & $4.1 \pm 0.4$ & $4.0 \pm 0.4$ \\
\hline Bradycardia (heart rate $<50$ beats/min) & $2(4.0 \%)$ & $2(3.9 \%)$ \\
\hline \multicolumn{3}{|l|}{ Left ventricle ejection fraction } \\
\hline$>49 \%$ & 48 (94.1\%) & 48 (92.3\%) \\
\hline $30-49 \%$ & $3(5.9 \%)$ & $4(7.7 \%)$ \\
\hline$<30 \%$ & $0(0.0 \%)$ & $0(0.0 \%)$ \\
\hline Preoperative QTc interval (ms) & $430.7 \pm 33.6$ & $425.2(29.7)$ \\
\hline Preoperative QTc interval > 500 ms & $0(0.0 \%)$ & $0(0.0 \%)$ \\
\hline Congenital long QT syndrome & $0(0.0 \%)$ & $0(0.0 \%)$ \\
\hline Duration of anaesthesia (min) & $449.7 \pm 44.2$ & $451.4 \pm 68.0$ \\
\hline
\end{tabular}


(Fig. 2), but were not different between the groups $(P=$ 0.210 and $P=0.178$, respectively). There were no intergroup differences regarding the use of ephedrine or phenylephrine during anaesthesia induction $(P=0.208$, and 0.603 , respectively), the use of inotropes or vasopressors at the end of surgery $(P=1.000$, and 1.000 , respectively), or total amount of infused fluid during the surgery $(P=0.666)$ (Table 2$)$.

\section{Perioperative QTc interval}

The changes in mean intraoperative QTc interval over time were not different between the groups $(P=0.591$, Fig. 3). However, maximal change in QTc interval during surgery was higher in the ramosetron group than the placebo group (mean difference $7.56 \mathrm{~ms}, 95 \%$ CI 0.3414.78, $P=0.040$, Fig. 4). The peak effect of ramosetron on QTc was observed at [median (IQR), $5(2-30)] \mathrm{min}$ after anaesthesia induction. Prolongation of QTc interval $>500 \mathrm{~ms}$ was not significantly different between groups. However, the number of patients with QTc interval increase $>60 \mathrm{~ms}$ was higher in the ramosetron group (risk difference $9.8 \%, 95 \%$ CI 1.6-18.0, $P=0.021$ ) (Table 3). Five patients with an increase in QTc $>60 \mathrm{~ms}$ had baseline QTc values of $381.4 \pm 36.0 \mathrm{~ms}$, whereas the patients with QTc $\leq 60 \mathrm{~ms}$ had baseline QTc values of $397.0 \pm 18.6 \mathrm{~ms}(P=0.086)$. When applying the Hodges formula, maximal change in QTc interval was higher in the ramosetron group with a marginal significance (mean difference $8.81 \mathrm{~ms}, 95 \% \mathrm{CI}-0.99-18.61, P=$ 0.077). Also, there were more patients with a QTc interval increase of $>60 \mathrm{~ms}$ in the ramosetron group (risk difference $9.8 \%, 95 \%$ CI 1.6-18.0, $P=0.021$ ) (Additional file 1 shows QTc interval by Fridericia's formula and Hodges formula). None of the patients experienced
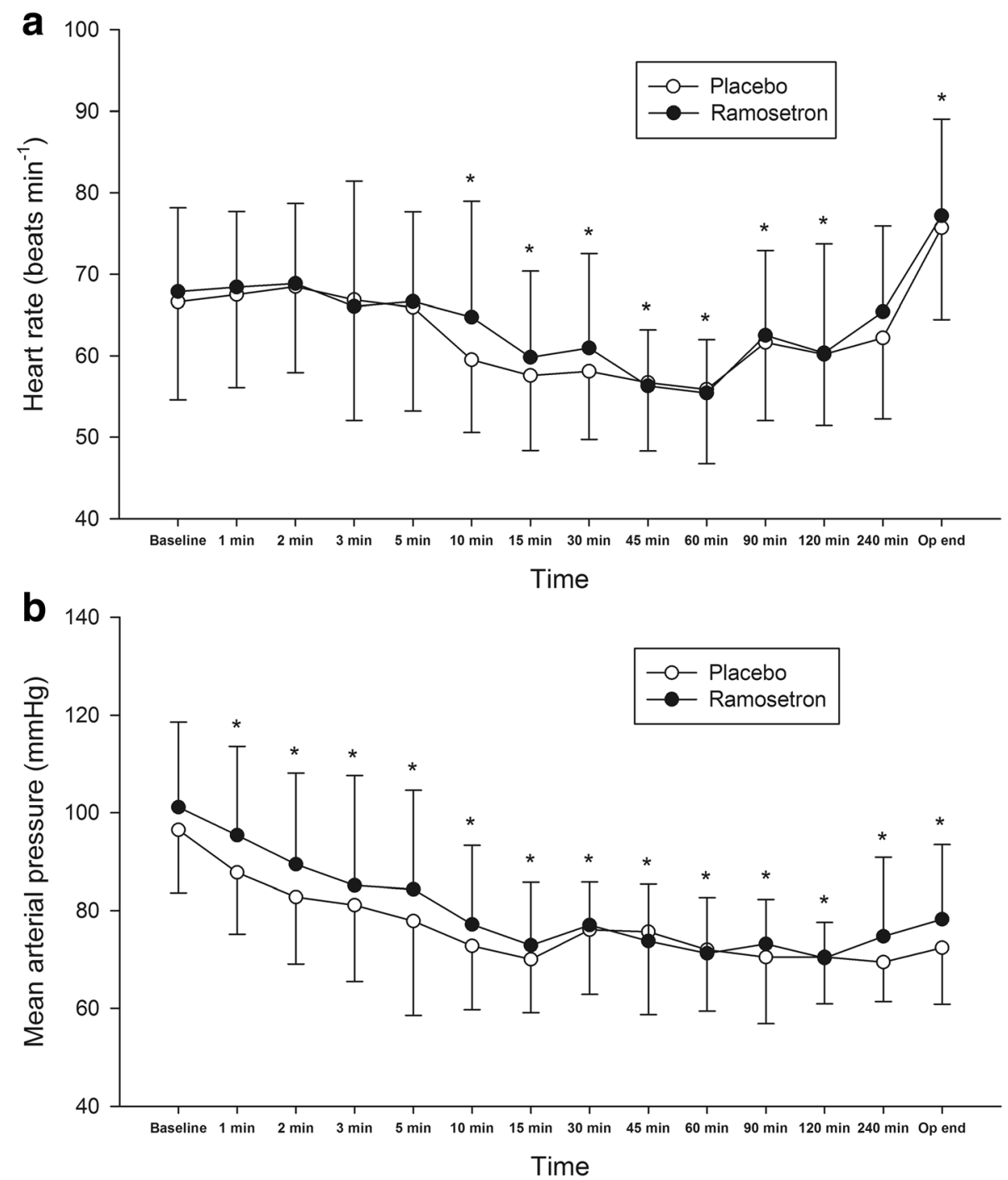

Fig. 2 Heart rate (a) and mean arterial pressure (b) during surgery. Values are shown as means (SD). ${ }^{*} P<0.05$ compared to baseline 
Table 2 Haemodynamic variables and fluids administered during surgery

\begin{tabular}{|c|c|c|c|}
\hline & Ramosetron $(n=51)$ & Placebo $(n=52)$ & $P$ value \\
\hline \multicolumn{4}{|l|}{ Before anaesthesia induction } \\
\hline Baseline heart rate (beats/min) & $66.1 \pm 10.6$ & $68.3 \pm 11.7$ & 0.317 \\
\hline Baseline mean arterial pressure $(\mathrm{mmHg})$ & $96.3 \pm 15.8$ & $101.1 \pm 14.6$ & 0.117 \\
\hline \multicolumn{4}{|l|}{ During anaesthesia induction } \\
\hline Use of ephedrine & $37(72.5 \%)$ & $31(60.8 \%)$ & 0.294 \\
\hline Use of phenylephrine & $8(15.7 \%)$ & $10(19.6 \%)$ & 0.796 \\
\hline \multicolumn{4}{|l|}{ At the end of surgery } \\
\hline Use of vasopressors & $1(1.9 \%)$ & $1(2.0 \%)$ & 1.000 \\
\hline Use of inotropes & $1(1.9 \%)$ & $1(2.0 \%)$ & 1.000 \\
\hline Number of grafts (n) & $3.6 \pm 0.7$ & $3.3 \pm 1.1$ & 0.120 \\
\hline Total infused fluids (ml) & $3671.2 \pm 1368.4$ & $3557.1 \pm 1308.9$ & 0.666 \\
\hline Total infused crystalloids (ml) & $3083.3 \pm 1699.3$ & $2992.5 \pm 1612.8$ & 0.781 \\
\hline Total infused colloids (ml) & $585.9 \pm 638.7$ & $526.2 \pm 814.6$ & 0.680 \\
\hline
\end{tabular}

Data are presented as mean \pm SD or number (proportion)

clinically significant arrhythmias requiring treatment during surgery.

\section{Postoperative in-hospital complications}

There were no significant differences between the groups in the incidences of postoperative arrhythmias, including atrial fibrillation, atrial flutter, ventricular tachycardia, ventricular fibrillation, bradycardia, and tachycardia (Table 4). The lengths of stay in the intensive care unit (ICU) and hospital, all components of MACCE, including death from cardiac causes, myocardial infarction, unplanned coronary revascularisation, and stroke, were not different between the groups (Table 4). However, this study was not powered to assess the effect of ramosetron on postoperative complications.

\section{Discussion}

In the present study, $0.3 \mathrm{mg}$ of intravenous ramosetron was associated with a significant increase of maximal change in QTc interval during OPCAB. Also, increase of the QTc interval of more than $60 \mathrm{~ms}$, which is considered to increase the risk of $\mathrm{TdP}$ was more frequently observed in the ramosetron group. There were no statistically significant differences in the intraoperative haemodynamic variables measured.

Most QTc interval prolonging drugs act by blocking the potassium channel encoded by the human ether-a-go-gorelated gene (hERG) [18]. 5- $\mathrm{HT}_{3}$ antagonists share the same potential proarrhythmic mechanisms. However, not all drugs in the $5-\mathrm{HT}_{3}$ antagonist class have clinically significant QTc-interval-prolonging effects. Ondansetron produced dose-related prolongation of QTc interval $[1,2]$, but granisetron and palonosetron did not induce significant

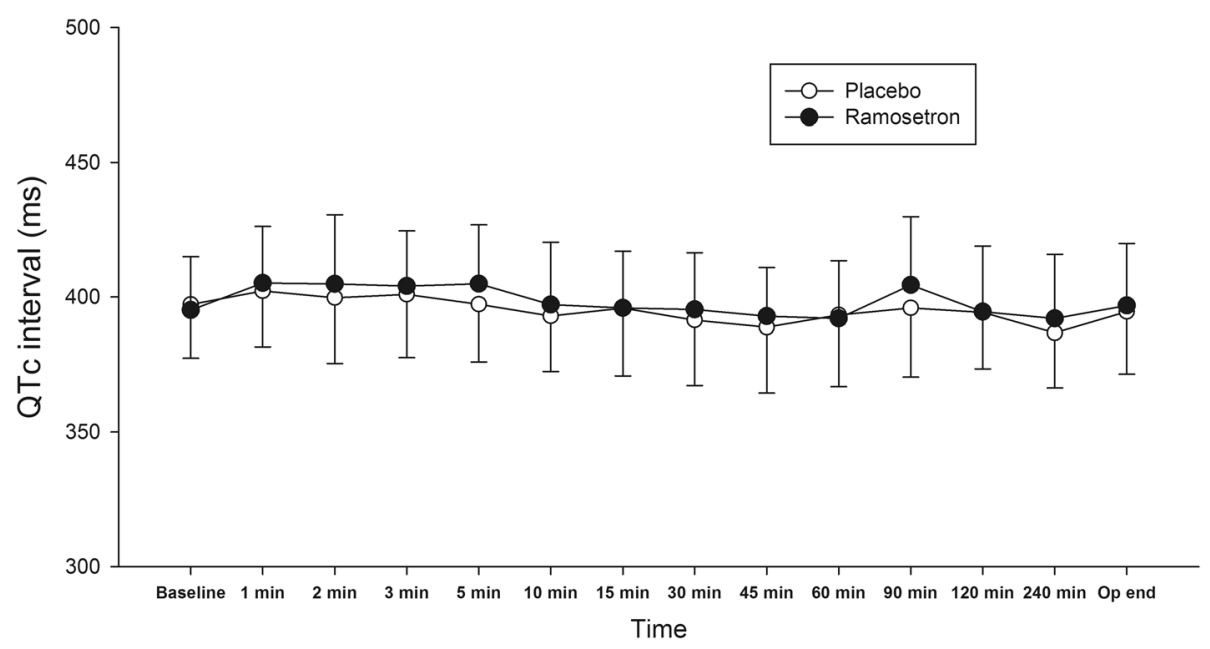

Fig. 3 QTC interval during surgery. Values are shown as means (SD) 


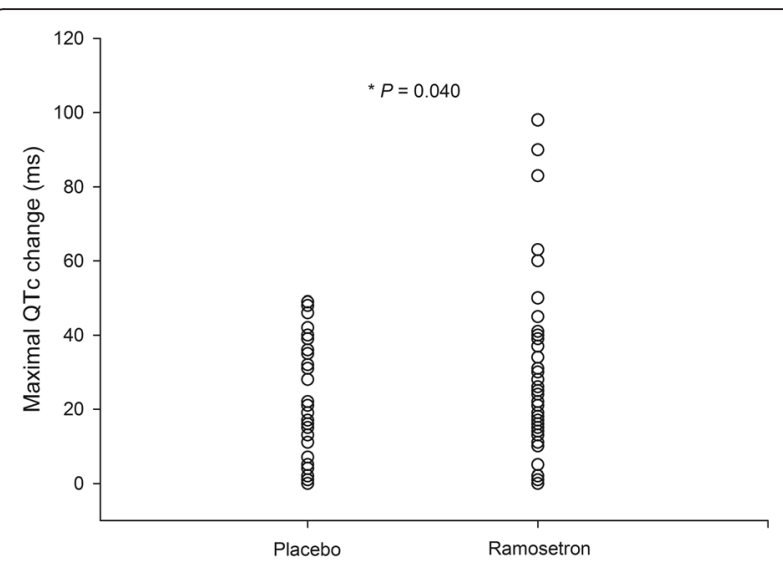

Fig. 4 Maximal change in QTc interval during surgery. Individual data points are superimposed within each group

QTc interval prolongation $[19,20]$. There are limited data regarding the effects of ramosetron on QTc interval in high-risk patients undergoing cardiac surgery.

Postoperative QTc interval prolongation was observed in $80 \%$ of patients undergoing noncardiac surgery [21]. Multiple drugs, including opioids, general anaesthetics, antibiotics, and cardioactive drugs, are associated with QT prolongation. In a recent study, QTc interval prolongation was common in patients undergoing cardiothoracic surgery [22]. However, this report did not describe the method of anaesthesia including the use of volatile anaesthetics, which prolong QTc interval and confound the effects of 5$\mathrm{HT}_{3}$ antagonists on QTc interval [12-14]. In the present study, general anaesthesia was maintained during surgery using continuous infusion of propofol and remifentanil, which are known to have minimal effects on QTc interval [14]. Mean intraoperative QTc intervals did not increase compared to baseline QTc value in both the ramosetron and placebo groups (Fig. 3). A previous study indicated that tracheal intubation caused significant prolongation of QTc interval during the anaesthetic induction period due to sympathetic stimulation [23]. However, in this study, tracheal intubation was performed $7.6 \pm 1.6 \mathrm{~min}$ after administration of ramosetron or placebo, and it did not significantly prolong QTc interval (Fig. 3). Sufentanil administered during anaesthetic induction may attenuate the sympathetic stimuli during tracheal intubation [24].

A recent study concluded that mean QTc interval did not increase after ramosetron administration in adult patients undergoing laparoscopic cholecystectomy, which was consistent with our results [25]. However, they did not compare the maximal changes in QTc interval. In this observational trial, the QTc interval was measured only during the last $10 \mathrm{~min}$ of surgery. To the best of our knowledge, there have been no randomised placebo controlled studies to investigate the effects of ramosetron on the QTc interval throughout the surgery.

In the present study, there were no differences in mean QTc interval between the ramosetron group and placebo group at every time point (Fig. 3). There were no differences in the measured intra- or postoperative outcomes. It is possible that the effect of QTc prolongation may not be so strong to be clinically significant. However, ramosetron increased the maximal change in QTc interval during the surgery, and there were more patients with a QTc interval increase of $>60 \mathrm{~ms}$ in the ramosetron group (Table 3 ). The findings were consistent with the other calculation methods, including Fridericia's, and Hodges formulas (Additional file 1). Given the effect of ramosetron on QTc interval, we have changed our clinical practice to avoid ramosetron in patients at high risk for developing TdP. Since intraoperative QTc interval prolongation was common, we recommend administering ramosetron at the end of surgery.

This study had several limitations. First, ramosetron was administered at the beginning of anaesthesia induction along with other drugs for induction of anaesthesia and possible drug-drug interactions may have confounded the effects of ramosetron on QTc interval. Moreover, a previous study indicated that propofol, which was continuously infused during surgery, may counteract the prolongation of QTc interval [26]. However, induction anaesthetics, including

Table 3 Changes in QTC interval during the surgery

\begin{tabular}{|c|c|c|c|c|}
\hline & \multicolumn{2}{|c|}{ Number of patients (\%) } & \multirow[b]{2}{*}{ Risk difference $(95 \% \mathrm{Cl})$} & \multirow[b]{2}{*}{$P$ value } \\
\hline & Ramosetron $(n=51)$ & Placebo $(n=52)$ & & \\
\hline QTc interval prolongation $>500 \mathrm{~ms}$ & $1(2.0 \%)$ & $0(0.0 \%)$ & $2.0 \%(-1.8$ to 5.8$)$ & 0.495 \\
\hline QTc interval increase $>60 \mathrm{~ms}$ & $5(9.8 \%)$ & $0(0.0 \%)$ & $9.8 \%(1.6$ to 18.0$)$ & 0.021 \\
\hline \multirow[t]{2}{*}{ QTc interval increase $>30 \mathrm{~ms}$} & $13(25.5 \%)$ & $12(23.1 \%)$ & $2.4 \%(-14.2$ to 19.0$)$ & 0.775 \\
\hline & Mean (SD) & & Mean difference $(95 \% \mathrm{Cl})$ & \\
\hline Baseline QTc interval before injection (ms) & $395.1 \pm 19.7$ & $397.2 \pm 19.8$ & $-2.09(-9.85$ to 5.66$)$ & 0.593 \\
\hline Maximal change in QTc interval (ms) & $25.1 \pm 22.0$ & $17.5 \pm 14.5$ & 7.56 (0.34 to 14.78$)$ & 0.040 \\
\hline QTc interval at postoperative day 1 (ms) & $428.9 \pm 59.0$ & $437.9 \pm 56.3$ & $-9.02(-33.32$ to 15.28$)$ & 0.463 \\
\hline
\end{tabular}

Data are presented as mean \pm SD or number (proportion). $\mathrm{Cl}$, confidence interval 
Table 4 Postoperative in-hospital complications

\begin{tabular}{|c|c|c|c|c|}
\hline & Ramosetron $(n=51)$ & Placebo $(n=52)$ & RR $(95 \% \mathrm{Cl})$ & $P$ value \\
\hline Atrial fibrillation & $11(21.6 \%)$ & $14(26.9 \%)$ & $0.80(0.40$ to 1.60$)$ & 0.647 \\
\hline Atrial flutter & $1(2.0 \%)$ & $1(1.9 \%)$ & 1.02 (0.07 to 15.87$)$ & 1.000 \\
\hline Ventricular tachycardia & $0(0.0 \%)$ & $0(0.0 \%)$ & & \\
\hline Ventricular fibrillation & $0(0.0 \%)$ & $0(0.0 \%)$ & & \\
\hline Bradycardia (heart rate $<50$ beats/min) & $0(0.0 \%)$ & $2(3.8 \%)$ & & 0.495 \\
\hline Tachycardia (heart rate $>100$ beats/min) & $5(9.8 \%)$ & $8(15.4 \%)$ & $0.64(0.22$ to 1.82$)$ & 0.555 \\
\hline Death from cardiac causes & $0(0.0 \%)$ & $0(0.0 \%)$ & & \\
\hline Myocardial infarction & $0(0.0 \%)$ & $0(0.0 \%)$ & & \\
\hline Unplanned coronary revascularisation & $0(0.0 \%)$ & $1(1.9 \%)$ & & 1.000 \\
\hline Stroke & $1(2.0 \%)$ & $1(1.9 \%)$ & 1.02 (0.07 to 15.87$)$ & 1.000 \\
\hline Intensive care unit length of stay (day) & $2(1$ to 3$)$ & $2(1$ to 4$)$ & & 0.912 \\
\hline Hospital length of stay (day) & $9(7$ to 13$)$ & 8.5 (7 to 13.75$)$ & & 0.350 \\
\hline
\end{tabular}

Data are presented as number (proportion) or median (IQR). Cl, confidence interval; RR, relative risk

midazolam, vecuronium, and sufentanil, are known to have minimal effects on QTc interval [27, 28], and we did not use volatile anaesthetics that are known to prolong QTc interval during this study [12-14]. Second, intraoperative factors, some of which may be difficult to control for, may have affected QTc interval. Surgical stress itself may also contribute to QTc interval [29]. Third, the QTc interval varies between leads, and the most appropriate lead to measure the QTc interval has not been established.

\section{Conclusion}

Ramosetron $(0.3 \mathrm{mg})$ administered during induction of anaesthesia may increase maximal change in QTc interval during OPCAB. Ramosetron should be used with caution in high risk patients for developing TdP.

\section{Additional file}

Additional file 1: QTc interval by Fridericia's formula and Hodges formula. (DOCX $17 \mathrm{~kb}$ )

\section{Abbreviations}

5-HT3, 5-Hydroxytryptamine 3; hERG, human ether-a-go-go-related gene; ICU, intensive care unit; MACCE, major adverse cardiovascular and cerebral events; OPCAB, off-pump coronary artery bypass graft; PONV, postoperative nausea and vomiting; TdP, torsades de pointes

\section{Acknowledgements}

We thank to Medical Research Collaborating Center (MRCC) of Seoul National University Hospital (Seoul National University Hospital, Seoul, Korea) for the statistical assistance and supervision.

\section{Funding}

The authors received no specific funding for this work.

\section{Availability of data and materials}

The datasets supporting the conclusions of this article are included within the article and its additional files.

\section{Authors' contributions}

TKK participated in study design, data analysis and drafted the manuscript. YJC participated in patient recruitment and drafted the manuscript. CWL participated in patient recruitment and data collection. $J \mathrm{JM}$ participated in the design of the study and performed the statistical analysis. EKC participated in data analysis and interpretation. DMH participated in the design of the study and performed the statistical analysis. YJ conceived of the study, and participated in its design and coordination and helped to draft the manuscript. All authors read and approved the final manuscript.

\section{Authors' information}

TKK is a clinical assistant professor of the department of Anaesthesiology and Pain Medicine at Seoul National University Hospital. YJC is a clinical instructor of the department of Anaesthesiology and Pain Medicine at Seoul National University Hospital. CWL is a public health doctor of the department of Anaesthesiology and Pain Medicine at Cheorwon Gil Hospital. JJM is a clinical instructor of the department of Anaesthesiology and Pain Medicine at Samsung Medical Centre. EKC is a clinical associate professor of the department of Internal Medicine at Seoul National University Hospital. DMH is an assistant professor of the department of Anaesthesiology and Pain Medicine at Seoul National University Hospital. YJ is an associate professor of the department of Anaesthesiology and Pain Medicine at Seoul National University Hospital.

\section{Competing interests}

The authors declare that they have no competing interests.

\section{Consent for publication}

Not applicable.

\section{Ethics approval and consent to participate}

Ethical approval for this study (protocol number: $\mathrm{H}-1304-101-483$ ) was provided by the institutional review board of Seoul National University Hospital, Seoul, Korea on 10 June 2013.

\section{Author details}

'Department of Anaesthesiology and Pain medicine, Seoul National University Hospital, Daehakro 101, Jongno-gu, Seoul 110-744, Korea. 2Department of Anaesthesiology and Pain Medicine, Cheorwon Gil Hospital, Gangwon-Do, Korea. ${ }^{3}$ Department of Anaesthesiology and Pain Medicine, Samsung Medical Centre, Seoul, Korea. ${ }^{4}$ Department of Internal Medicine, Seoul National University Hospital, Seoul, Korea.

Received: 22 June 2015 Accepted: 15 July 2016 Published online: 03 August 2016 


\section{References}

1. Charbit B, Alvarez JC, Dasque E, Abe E, Démolis JL, Funck-Brentano C. Droperidol and ondansetron-induced QT interval prolongation: a clinical drug interaction study. Anesthesiology. 2008;109(2):206-12.

2. Hafermann MJ, Namdar R, Seibold GE, Page 2nd RL. Effect of intravenous ondansetron on QT interval prolongation in patients with cardiovascular disease and additional risk factors for torsades: a prospective, observational study. Drug Healthc Patient Saf. 2011;3:53.

3. Couderc J-P, Xia J, Xu X, Kaab S, Hinteeser M, Zareba W. Static and dynamic electrocardiographic patterns preceding torsades de pointes in the acquired and congenital long QT syndrome. Comput Cardiol (2010). 2010;37:357-60.

4. Schouten EG, Dekker JM, Meppelink P, Kok FJ, Vandenbroucke JP, Pool J. QT interval prolongation predicts cardiovascular mortality in an apparently healthy population. Circulation. 1991;84(4):1516-23.

5. Straus SM, Kors JA, De Bruin ML, van der Hooft CS, Hofman A, Heeringa J, et al. Prolonged QTC interval and risk of sudden cardiac death in a population of older adults. J Am Coll Cardiol. 2006:47(2):362-7.

6. Chugh SS, Reinier K, Singh T, Uy-Evanado A, Socoteanu C, Peters D, et al. Determinants of prolonged QT interval and their contribution to sudden death risk in coronary artery disease the Oregon sudden unexpected death study. Circulation. 2009;1 19(5):663-70.

7. Choi DK, Chin JH, Lee EH, Lim OB, Chung CH, Ro YJ, et al. Prophylactic control of post-operative nausea and vomiting using ondansetron and ramosetron after cardiac surgery. Acta Anaesthesiol Scand. 2010;54(8):962-9.

8. Apfel CC, Kranke P, Eberhart LH, Roos A, Roewer N. Comparison of predictive models for postoperative nausea and vomiting. $\mathrm{Br} J$ Anaesth. 2002;88(2):234-40.

9. Yap YG, Camm AJ. Drug induced QT prolongation and torsades de pointes. Heart. 2003;89(11):1363-72.

10. Rabasseda X. Ramosetron, a 5-HT3 receptor antagonist for the control of nausea and vomiting. Drugs Today (Barc). 2002;38(2):75-89.

11. Mihara T, Tojo K, Uchimoto K, Morita S, Goto T. Reevaluation of the effectivenes of ramosetron for preventing postoperative nausea and vomiting: a systematic review and meta-analysis. Anesth Analg. 2013;117(2):329-39.

12. Kleinsasser A, Kuenszberg E, Loeckinger A, Keller C, Hoermann C, Lindner $\mathrm{KH}$, et al. Sevoflurane, but not propofol, significantly prolongs the QT interval. Anesth Analg. 2000;90(1):25.

13. Owczuk R, Wujtewicz MA, Sawicka W, Lasek J, Wujtewicz M. The influence of desflurane on QTc interval. Anesth Analg. 2005;101(2):419-22.

14. Yamada M, Hatakeyama N, Malykhina AP, Yamazaki M, Momose Y, Akbarali $H \mathrm{H}$. The effects of sevoflurane and propofol on QT interval and heterologously expressed human ether-a-go-go related gene currents in Xenopus oocytes. Anesth Analg. 2006;102(1):98-103.

15. Panicker GK, Salvi V, Karnad DR, Chakraborty S, Manohar D, Lokhandwala Y, Kothari S. Drug-induced QT prolongation when QT interval is measured in each of the 12 ECG leads in men and women in a thorough QT study. J Electrocardiol. 2014:47(2):155-7.

16. Al-Khatib SM, LaPointe NMA, Kramer JM, Califf RM. What clinicians should know about the OT interval. JAMA. 2003:289(16):2120-7.

17. Fenichel RR, Malik M, Antzelevitch C, Sanguinetti M, Roden DM, Priori SG, et al. Drug-induced torsades de pointes and implications for drug development. J Cardiovasc Electrophysiol. 2004;15(4):475-95.

18. Wood AJ, Roden DM. Drug-induced prolongation of the QT interval. N Engl J Med. 2004;350(10):1013-22.

19. Kim H, Lee $H-C$, Jung $Y$, Lee J, Min J, Hong D-M, et al. Effect of palonosetron on the QTc interval in patients undergoing sevoflurane anaesthesia. $\mathrm{Br}$ J Anaesth. 2014;112(3):460-8.

20. Mason JW, Selness DS, Moon TE, O'Mahony B, Donachie P, Howell J. Pharmacokinetics and repolarization effects of intravenous and transdermal granisetron. Clin Cancer Res. 2012;18(10):2913-21.

21. Nagele P, Pal S, Brown F, Blood J, Miller JP, Johnston J. Postoperative QTinterval prolongation in patients undergoing non-cardiac surgery under general anesthesia. Anesthesiology. 2012;117(2):321.

22. Toma M, Marstrand P, Holmenlund K, Umar S, Wanscher M. QT interval prolongation after cardiac surgery; an interesting biological phenomenon or a clinical problem? Data from the Prolonqit study. J Clin Toxicol. 2014:4:195. doi:10.4172/2161-0495.1000195.

23. Lindgren L, Yli-Hankala A, Randell T, Kirvelä M, Scheinin M, Neuvonen P. Haemodynamic and catecholamine responses to induction of anaesthesia and tracheal intubation: comparison between propofol and thiopentone. $\mathrm{Br}$ J Anaesth. 1993;70(3):306-10.
24. Chang D, Kweon T, Nam S, Lee J, Shin C, Park C, et al. Effects of fentanyl pretreatment on the QTc interval during propofol induction. Anaesthesia. 2008;63(10):1056-60

25. Kim S-H, Lee S-M, Kim Y-K, Park S-Y, Lee J-H, Cho S-H, et al. Effects of prophylactic ramosetron and ondansetron on corrected QT interval during general anesthesia. J Clin Anesth. 2014;26(7):511-6.

26. Kleinsasser A, Loeckinger A, Lindner $K$, Keller C, Boehler M, Puehringer F. Reversing sevoflurane-associated Q-Tc prolongation by changing to propofol. Anaesthesia. 2001;56(3):248-50.

27. Michaloudis D, Kanakoudis F, Xatzikraniotis A, Bischiniotis T. The effects of midazolam followed by administration of either vecuronium or atracurium on the QT interval in humans. Eur J Anaesthesiol. 1995;12(6):577-83.

28. Weber G, Stark G, Stark U. Direct cadiac electorphysiologic effects of sufentanil and vecuronium in isolated guinea-pig hearts. Acta Anaesthesiol Scand. 1995; 39(8):1071-4.

29. Magnano AR, Talathoti N, Hallur R, Bloomfield DM, Garan H. Sympathomimetic infusion and cardiac repolarization: the normative effects of epinephrine and isoproterenol in healthy subjects. J Cardiovasc Electrophysiol. 2006;17(9):983-9.

\section{Submit your next manuscript to BioMed Central and we will help you at every step:}

- We accept pre-submission inquiries

- Our selector tool helps you to find the most relevant journal

- We provide round the clock customer support

- Convenient online submission

- Thorough peer review

- Inclusion in PubMed and all major indexing services

- Maximum visibility for your research

Submit your manuscript at www.biomedcentral.com/submit
C) Biomed Central 